\title{
UvAtg8-Mediated Autophagy Regulates Fungal Growth, Stress Responses, Conidiation, and Pathogenesis in Ustilaginoidea virens
}

Shuai Meng ${ }^{1}$, Meng Xiong ${ }^{2}$, Jane Sadhna Jagernath ${ }^{1}$, Congcong Wang ${ }^{1}$, Jiehua Qiu', Huanbin Shi ${ }^{1}$ and Yanjun $\mathrm{Kou}^{1 *}$ (D)

\begin{abstract}
Background: Ustilaginoidea virens has become one of the most devastating rice pathogens in China, as well as other rice-growing areas. Autophagy is an important process in normal cell differentiation and development among various organisms. To date, there has been no optimized experimental system introduced for the study of autophagy in $U$. virens. In addition, the function of autophagy in pathogenesis remains unknown in U. virens. Therefore, the functional analyses of UvAtg8 may potentially shed some light on the regulatory mechanism and function of autophagy in $U$. virens.

Results: In this study, we characterized the functions of UvAtg8, which is a homolog of Saccharomyces cerevisiae ScAtg8, in the rice false smut fungus $U$. virens. The results showed that UVATG8 is essential for autophagy in U. virens. Also, the GFP-UVATG8 strain, which could serve as an appropriate marker for monitoring autophagy in U. virens, was generated. Furthermore, this study found that the $\Delta U$ vatg8 mutant was defective in the vegetative growth, conidiation, adaption to oxidative, hyperosmotic, cell wall stresses, and production of toxic compounds. Pathogenicity assays indicated that deletion of UVATG8 resulted in significant reduction in virulence of $U$. virens. Further microscopic examinations of the infection processes revealed that the severe virulence defects in the $\Delta$ Uvatg 8 were mainly caused by the highly reduced conidiation and secondary spore formation.
\end{abstract}

Conclusions: Our results indicated that the UvAtg8 is necessary for the fungal growth, stresses responses, conidiation, secondary spore formation, and pathogenicity of U. virens. Moreover, our research finding will potentially assist in further clarifying the molecular mechanism of $U$. virens infection, as well as provide a good marker for autophagy in $U$. virens and a good reference value for the further development of effective fungicides based on gene targeting.

Keywords: UvAtg8, Rice false smut, Ustilaginoidea virens, Autophagy, Secondary spore, Pathogenicity

\footnotetext{
* Correspondence: kouyanjun241@hotmail.com

'State Key Laboratory of Rice Biology, China National Rice Research Institute, Hangzhou 311400, China

Full list of author information is available at the end of the article
}

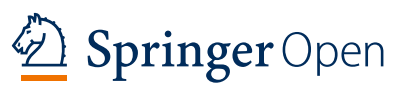

(c) The Author(s). 2020 Open Access This article is licensed under a Creative Commons Attribution 4.0 International License, which permits use, sharing, adaptation, distribution and reproduction in any medium or format, as long as you give appropriate credit to the original author(s) and the source, provide a link to the Creative Commons licence, and indicate if changes were made. The images or other third party material in this article are included in the article's Creative Commons licence, unless indicated otherwise in a credit line to the material. If material is not included in the article's Creative Commons licence and your intended use is not permitted by statutory regulation or exceeds the permitted use, you will need to obtain permission directly from the copyright holder. To view a copy of this licence, visit http://creativecommons.org/licenses/by/4.0/. 


\section{Introduction}

Rice false smut disease is caused by the ascomycete fungal pathogen Ustilaginoidea virens. It is currently one of the most devastating rice fungal diseases in China, as well as many other countries (Fan et al. 2016; Jia et al. 2014; Ladhalakshmi et al. 2012; Nessa et al. 2015; Qiu et al. 2019). The typical and only visible symptom of rice false smut disease is the replacement of rice grains with false smut balls. The occurrence of rice false smut disease not only results in decrease of rice quality and serious loss of rice yield, but also threatens food safety due to its production of toxic mycotoxins ( $\mathrm{Lu}$ et al. 2015; Lin et al. 2018; Meng et al. 2015; Wang et al. 2017; Sun et al. 2017). However, it has been found that the rice false smut disease is difficult to control. This is due to the fact that no resistant genes or completely immune rice varieties for rice false smut disease have yet been identified. Therefore, it is more and more important to deepen the understanding of the pathogenic mechanism of $U$. virens in order to provide clues for the development of more effective strategies to control the disease.

Autophagy is a tightly controlled catabolic cellular process which promotes homeostasis and adaptation by quality and quantity control of cytoplasmic components (Liu et al. 2016; Zong et al. 2016; Hofius et al. 2017). During the processes of autophagy, cytosolic materials, including damaged proteins and organelles, are captured by double membrane phagophore, which is followed by targeting to the vacuoles or lysosomes for degradation and recycling. After the degradation by resident hydrolases, the recycled components can be used for the synthesis of new molecules and/or providing energy source. Autophagy is involved in many important processes, including cell differentiation, development, and responses to nutrient starvation. The disruption of autophagy leads to impaired pathogenesis in some plant fungal pathogens (Sumita et al. 2017; Shi et al. 2019; Ren et al. 2018; Nadal and Gold 2010; Josefsen et al. 2012; Deng et al. 2009; Liu et al. 2016; Zhu et al. 2019).

Over the past two decades, the molecular mechanisms and machinery required for autophagosomal biogenesis and the subsequent degradation of cargo have been well characterized. In previous studies, more than 40 autophagy related (ATG) genes have been identified, which are necessary for this complex process (Liu et al. 2016; Zong et al. 2016; Hofius et al. 2017). Among those genes, ATG8 (referred to as the LC3/GABARAP protein in humans), which encodes an ubiquitin-like protein, is a key component of the autophagy pathway (Ichimura et al. 2000). During autophagy, Atg8 is processed by the protease Atg4 and conjugated to the membrane lipid phosphatidylethanolamine (PE) through an ubiquitylationlike reaction, which is catalyzed by the E1-like enzyme Atg7, E2-like enzyme Atg3, and an E3-like complex
Atg12-Atg5-Atg16 (Yoshimura et al. 2006; Ichimura et al. 2000; Hanada et al. 2007). The lipidated Atg8 mediates the tethering and hemifusion of membranes leading to autophagosome maturation (Nakatogawa et al. 2007).

In several plant pathogenic fungi, Atg8 is involved in various physiological processes, including cell differentiation, fungal development, secondary metabolism, and pathogenesis. In Magnaporthe oryzae, which is an important fungal pathogen of rice, Atg8-mediated autophagy is necessary for conidiation, formation of infection structure, and penetration (Veneault-Fourrey et al. 2006; Deng et al. 2009) (Veneault-Fourrey et al. 2006, Deng et al. 2009). For Ustilago maydis, which causes corn smut disease, Atg8 is required for proper morphogenesis and pathogenicity (Nadal and Gold 2010). In addition, deletion of FgATG8 results in reduced hyphal growth, reproductive growth, and myctoxin biosynthesis in the destructive wheat pathogen Fusarium graminearum (Josefsen et al. 2012). In Bipolaris maydis, responsible for southern corn leaf blight, BmAtg8 plays a crucial role in the function of conidia, but not in the host infection via appressoria (Sumita et al. 2017). In Botrytis cinerea, the mutant lacking of BcATG8 shows defects in fungal development, lipid metabolism, and pathogenesis (Ren et al. 2018). In the chest blight fungus Cryphonectria parasitica, CPATG8 is not only required for pathogenesis but also is involved in hypovirus accumulation (Shi et al. 2019).

Despite the knowledge of autophagy and Atg8 in various fungi, its role in the rice fungal pathogen $U$. virens remains obscure. In this study, UvAtg8, a ScAtg8 homologue, was identified in $U$. virens and for the first time an experimental system was optimized to elucidate the function of autophagy in phytopathogenic $U$. virens. Our results indicated that UvAtg8 mediated autophagy played important roles in the growth, stresses responses, production of toxic compounds, conidiation, secondary spore formation, and pathogenicity of $U$. virens.

\section{Results}

\section{Identification of UvAtg8}

To identify the Atg8 homologous protein in $U$. virens, the amino acid sequence of Atg8 (GenBank KZV12988) from Saccharomyces cerevisiae was used as a query for the BLASTP search on NCBI. The KDB12146.1 (termed as UvAtg8) was hit as the ortholog of S. cerevisiae Atg8 with $78 \%$ identity and $90 \%$ similarity (Fig. 1a). UvAtg8 consists of 121 amino acids. Sequence analysis using motif scan (https://myhits.isb-sib.ch/cgi-bin/motif_scan) revealed that UvAtg8 contained a MAP 1_LC3 domain between 13 and 116 amino acids. The phylogenetic analysis results of the amino acid sequences of Atg8 from $U$. virens, F. graminearum, Aspergillus niger, Neurospora crassa, Metarhizium brunneum, Sclerotinia sclerotiorum, 
$\mathbf{a}$
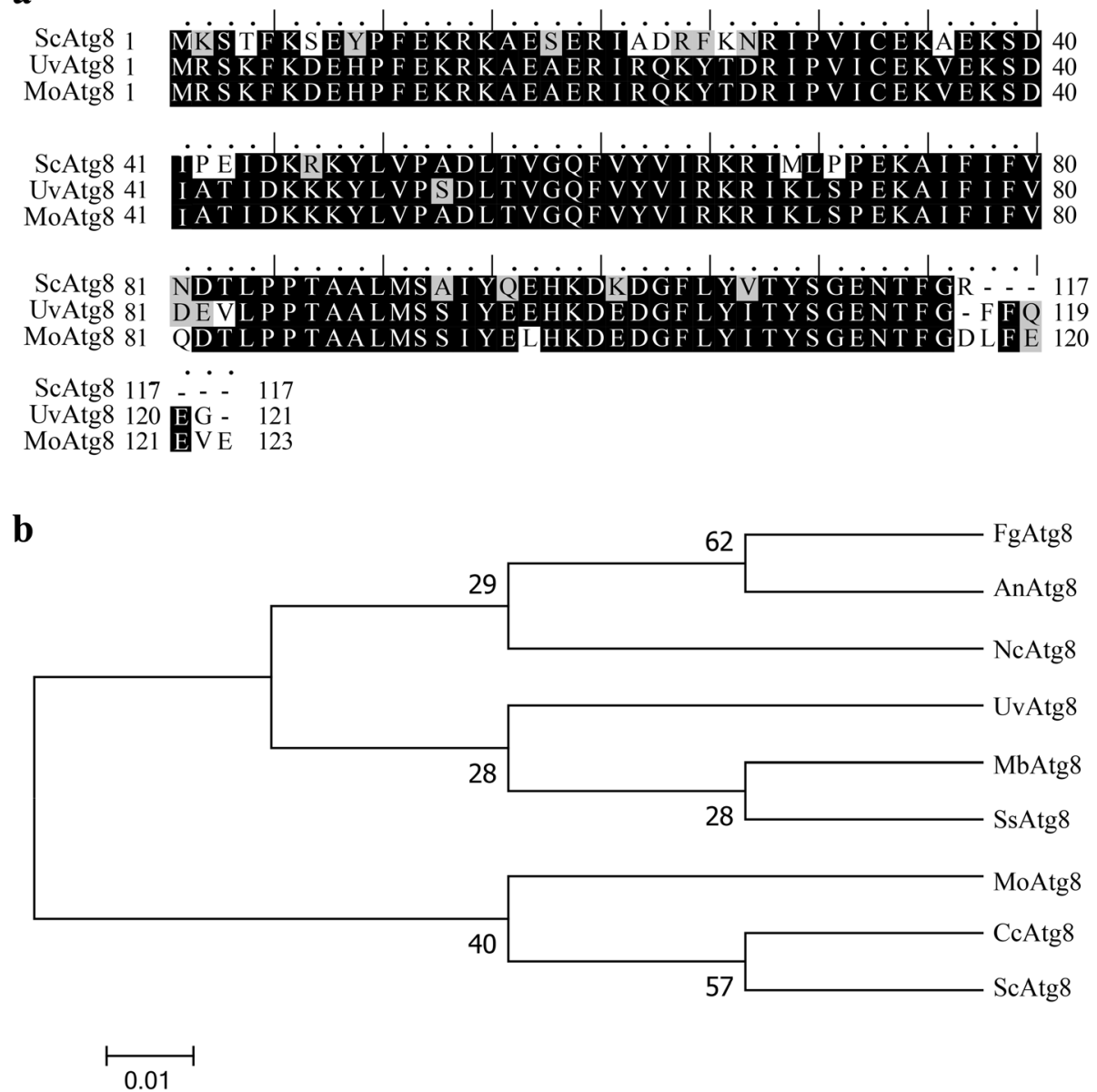

Fig. 1 Evolution analysis of UvAtg8. a, The mutiple alignment of amino acid sequences of UvAtg8, ScAtg8, and MoAtg8. The identitical amino acid were shaded in solid black, and the amino acids with $50 \%$ similarity were highlighted in gray. b, Phylogenetic tree of Atg 8 orthologs from different fungi was constructed by MEGA 5.0 using the neighbour-joining method. The sequences included FgAtg8 (Fusarium graminearum, XP_001392077.1), AnAtg8 (Aspergillus niger, XP_001392077.1), NcAtg8 (Neurospora crassa, XP_956248.1), UvAtg8 (Ustilaginoidea virens, KDB12146.1), MbAtg8 (Metarhizium brunneum, XP_014545792.1), SsAtg8 (Sclerotinia sclerotiorum, XP_001597408.1), MoAtg8 (Magnaporthe oryzae,

XP_003717877.1), CcAtg8 (Coprinopsis cinerea, XP_001833603.1), and ScAtg8 (Saccharomyces cerevisiae, NP_009475.1)

M. oryzae, Coprinopsis cinerea, and S. cerevisiae, revealed that UvAtg8 protein was most similar to Atg8 of M. brunneum and S. sclerotiorum. These results indicated that Atg8 is highly conserved in different species, and also suggested that UvAtg8 may have important functions in $U$. virens (Fig. 1b).

\section{Disruption and Complementation of UvATG8}

To understand the biological functions of UvATG8, UvATG8 deletion mutants were generated by targeted gene replacement in the wild type (WT) HWD-2 strain (Fig. 2a). Southern blot assay was performed to confirm the targeted gene replacement events and excluding ectopic integrations. The appearance of the $3.8 \mathrm{~Kb}$ (kilobases) band in the $\Delta U$ vatg8 mutant, with concomitant loss of the WT $2.4 \mathrm{~Kb}$ in UvATG8 locus, indicated that the gene replacement event was correct (Fig. 2b). The resultant three $\Delta U$ vatg8 mutants showed comparable phenotypes and formed smaller colonies than the WT, and $\Delta$ Uvatg8-36 and 102 were chosen for further experiments.

To confirm that the phenotypic differences observed in the $\Delta U$ vatg8 mutants were all associated with the gene replacement event, a vector pFGL820-UvATG8 containing a full-length gene copy of UvATG8 with its native promoter was transformed into $\Delta U v \operatorname{vatg} 8-36$. The resultant $\Delta U$ vvatg8-C strain was further confirmed using qRT-PCR (quantitative Real-time PCR) assay. The expression levels of UvATG8 in the WT and $\Delta$ Uvatg8-C strain were comparable, which indicated that $\Delta U v a t g 8-C$ had rescued the expression of $U v A T G 8$ (Fig. 2c). Moreover, the $\Delta$ Uvatg8-C strain was similar to the WT strain in colony morphology, suggesting that $\Delta U v a t g 8-C$ functionally complemented the phenotype of $\Delta$ Uvatg8. 


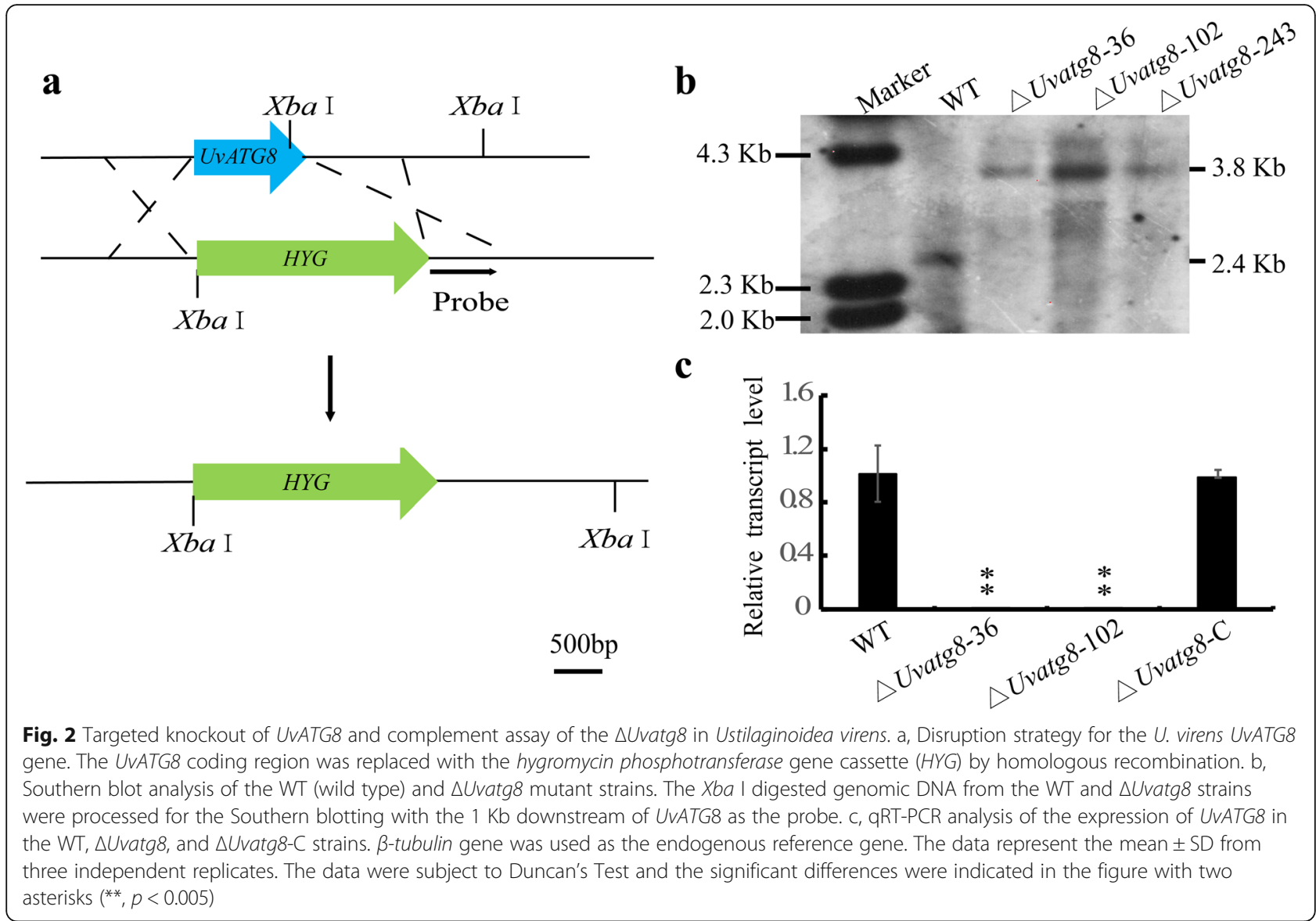

\section{UvAtg8 Could Sever as a Marker for Autophagy in U. virens}

Atg8 is known to be one of the key components of autophagy (Liu et al. 2016; Zong et al. 2016; Hofius et al. 2017). To determine whether UvATG8 is required for autophagy in $U$. virens, the changes in the process of autophagy in the WT and $\Delta U v \operatorname{vatg} 8-\mathrm{C}$ strains were determined using microscopy (Fig. 3a). When cultured in SD$\mathrm{N}$ (synthetic dropout medium without nitrogen) liquid medium in the presence of $3 \mathrm{mM}$ PMSF (Phenylmethanesulfonyl fluoride) for $4 \mathrm{~h}$, less than $10 \%$ of the vacuoles had a very few autophagic bodies in the $\Delta U$ vatg $8 \mathrm{mu}-$ tant. In contrast, nearly $65 \%$ of the vacuoles in the WT strain exhibited multiple autophagic bodies. These results suggested that the autophagic pathway was blocked in the $\Delta U$ vvatg8 mutant.

To observe the localization of UvAtg8, the $U$. virens strain expressing GFP-UvAtg8 fusion protein under native regulation and as the sole copy of UvATG8 was generated. The size of GFP-UvAtg8 protein was correct and the morphologies of the GFP-UvATG8 strain were comparable to the WT strain, indicating that the GFPUvAtg8 fusion protein was functional in $U$. virens. In order to induce autophagy, the GFP-UvATG8 strain was cultured in a liquid PS (Potato sucrose) medium for 2 $\mathrm{d}$, and then inoculated into the SD-N medium in the presence of $3 \mathrm{mM}$ PMSF. During the growth process in the PS medium, the GFP signals were weak and in punctate structures in the GFP-UvATG8 strain. However, following the growth in SD-N medium for $12 \mathrm{~h}$, the GFP fluorescent signals increased and could be easily observed in the CMAC (7-amino-4-chloromethylcoumarin) stained vacuoles (Fig. 3c, d). These results indicated that the GFP-UvAtg8 was localized in the cytoplasm as pre-autophagosomal structures under general conditions, but were predominantly accumulated in the lumen of the vacuoles under nitrogen starvation condition.

Next, the Western blot assay was performed to analyze the expression of GFP-UvAtg8 with anti-GFP antibody under both normal and nitrogen starvation conditions. Based on the predicted sizes and relative mobility, the two detected bands were judged to be the full-length GFP-UvAtg8 and likely the free GFP (Fig. 3b). The stronger GFP band indicated enhanced expression and degradation of the GFP-UvAtg8 in the SD-N medium, and indirectly showed enhanced autophagic response in $U$. virens under nitrogen starvation condition. 


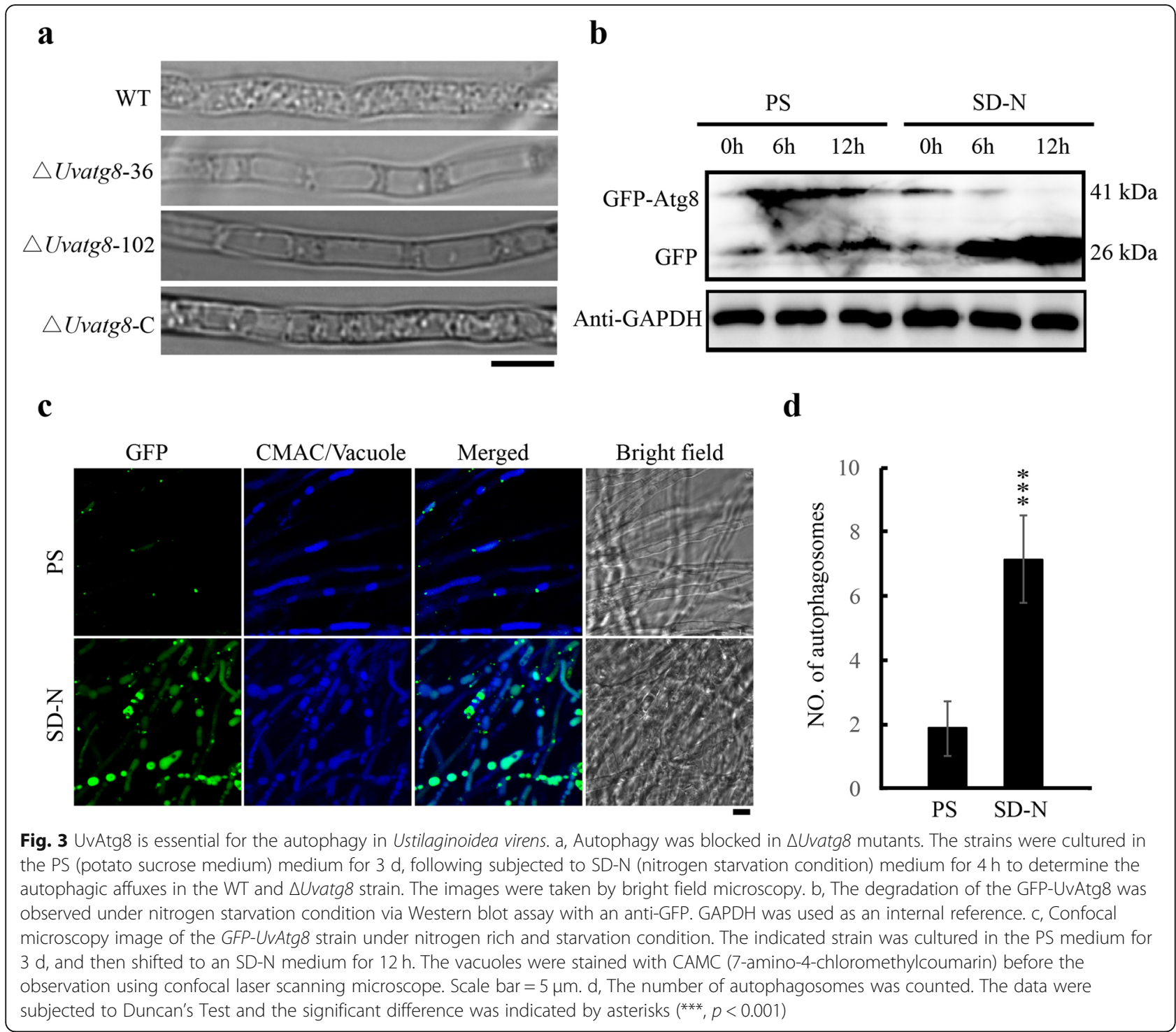

Taken together, these results suggested that UvAtg8 is essential for autophagy in $U$. virens, and GFP-UvAtg8 could serve as an appropriate marker for monitoring autophagy in $U$. virens as GFP/RFP-Atg8 in other organisms (Deng et al. 2009; Zong et al. 2016).

\section{UvAtg8 Plays Important Roles in Vegetative Growth}

Because the $\Delta$ Uvatg8 mutants had formed smaller colonies than the WT strain, the vegetative growth of the WT, $\Delta U v a t g 8$, and $\Delta U v a t g 8-C$ strains were determined using different mediums. The $\Delta U$ vatg 8 strain was slightly reduced in mycelia growth when compared with that of the WT strain on the PSA. However, the mycelia growths of the $\Delta$ Uvatg8 strain on the SD and SD-N medium were significantly reduced (Fig. 4a,b). Notably, the inhibition rate of the $\Delta U v a t g 8$ strain was significantly increased when compared with that of the WT strain under the nitrogen starvation condition, which indicated that its defects in hypha growth were partially dependent on the nutrient conditions (Fig. 4a,c). In contrast, the mycelia growth and colony morphology were rescued in the $\Delta U v a t g 8-C$ strain (Fig. 4), suggesting that UvAtg8 plays important roles in the vegetative growth of U. virens.

\section{UvAtg8 Is Involved in Various Stress Responses}

Autophagy is known to be related to several stress responses (Yin et al. 2019). However, it remains unclear whether $U v A T G 8$ regulates stress responses of $U$. virens. Therefore, the sizes of $\Delta U v a t g 8$ colonies were measured under different stress conditions, including oxidative, hyperosmotic, and cell wall stresses. In the presence of $0.03 \% \mathrm{H}_{2} \mathrm{O}_{2}$, the growth was reduced by $50 \%$ in the WT strain, but approximately $75 \%$ in the $\Delta U v \operatorname{vatg} 8$ mutant 

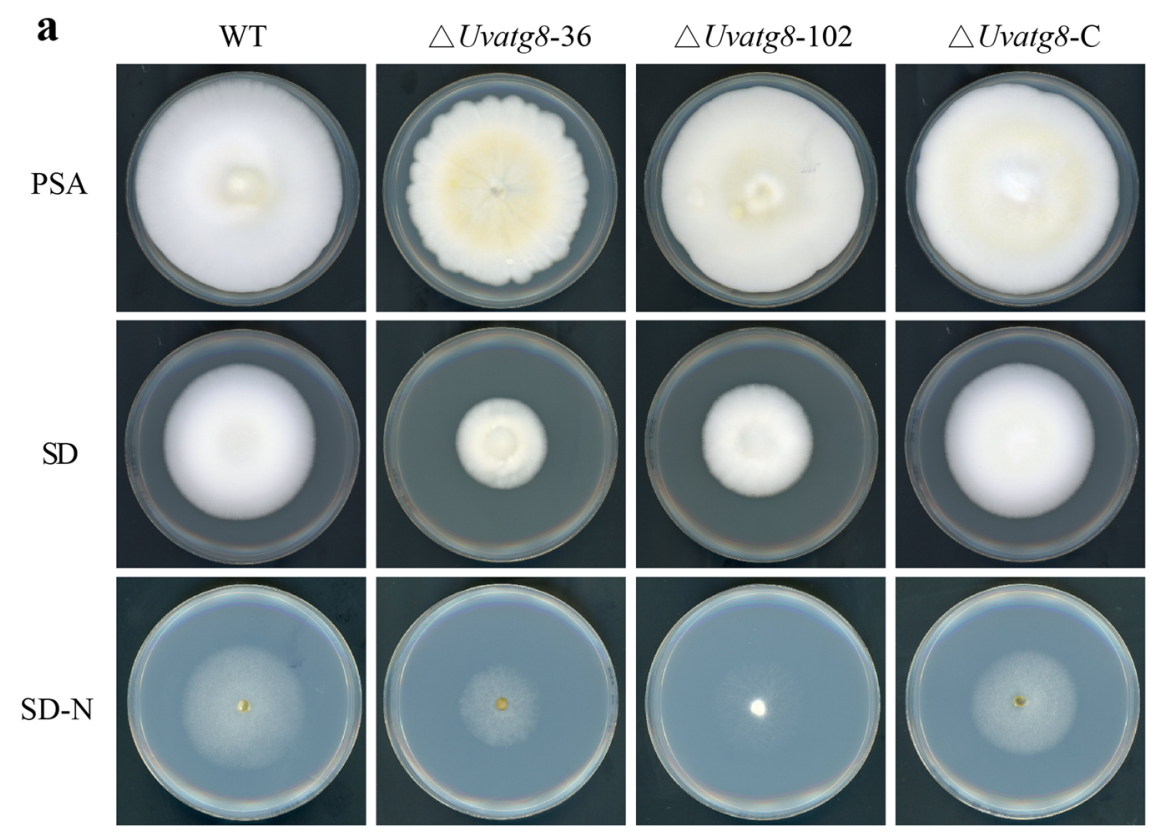

b

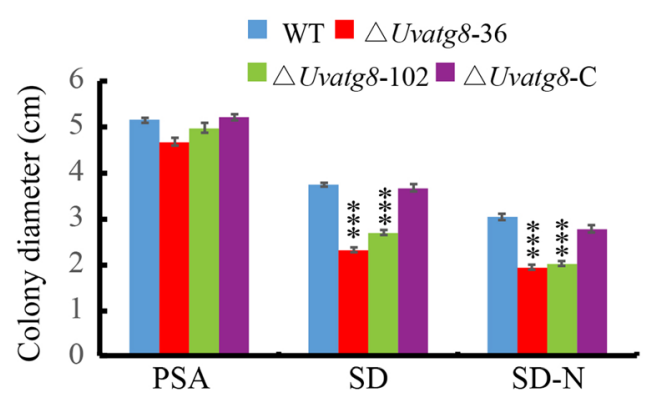

c

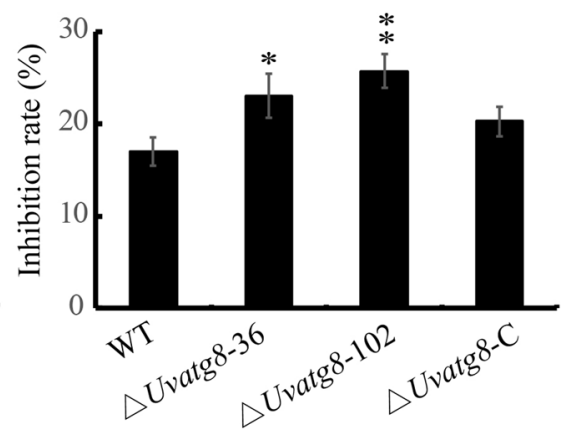

Fig. 4 UvAtg8 plays important roles in the fungal growth. a, Radial growth of $\triangle U$ Uvatg 8 was reduced. Colonies of the WT, $\triangle U$ Uvatg8, and $\triangle U$ vatg8-C strains were grown on the PSA、SD and SD-N medium in dark for $15 \mathrm{~d}$ and then imaged. b, Statistical analysis of colonies diameters of test strains on the PSA, SD and SD-N plates. C, Statistical analysis of inhibition rate of test strains under nitrogen starvation condition by comparing the fungal growth on the SD-N and SD medium. Three independent biological experiments were performed with three replicates each time. The data were subjected to Duncan's Test and the significant differences were shown in the figure with asterisks $\left({ }^{*}, p<0.01 ;{ }^{* *}, p<0.005\right.$; ***, $p<0.001)$

after incubation for $15 \mathrm{~d}$ (Fig. 5). These results indicated that the $\Delta U$ vatg8 was sensitive to oxidative stress. Similarly, both the $\Delta$ Uvatg8-36 and 102 had shown significantly increased inhibitory effects when compared with the WT strain on the medium with $0.4 \mathrm{M} \mathrm{NaCl}$ or $0.7 \mathrm{M}$ Sorbitol (Fig. 5), thereby suggesting that UvATG8 contributed to the adaptions to the hyperosmotic stresses. In addition, the deletion of UvATG8 resulted in decreased tolerance to different cell wall stresses (Fig. 5), including 0.03\% Sodium dodecyl sulfate (SDS), $200 \mu \mathrm{g} /$ $\mathrm{mL}$ Calcofluor white (CFW), and $240 \mu \mathrm{g} / \mathrm{mL}$ Congo Red $(\mathrm{CR})$, in $U$. virens. The complementation strain $\Delta$ Uvatg8-C showed similar phenotypes as the WT strain under all of the observed stress conditions. All the aforementioned results indicated that UvAtg8 is involved in the adaptions to oxidative, hyperosmotic, and cell wall stresses in $U$. virens.

\section{UvAtg8 Is Required for Pathogenesis in $U$. virens}

To investigate the roles of UvATG8 in the virulence of $U$. virens, infection assays were performed. The WT, $\Delta U$ vatg8-36 and 102, and $\Delta U v$ vatg8-C strains were inoculated into panicles of the susceptible rice cultivar Wanxian 98. The formation of rice false smut balls were calculated 3 weeks after the inoculations. Remarkably, the numbers of smut balls in the $\Delta U v a t g 8-36$ and 102 strains were significantly lower than those in the WT and complementation strains (Fig. 6a). Therefore, 
a

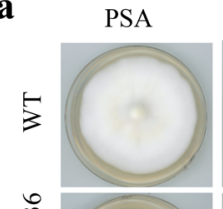

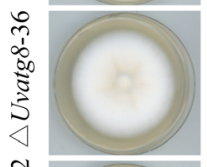

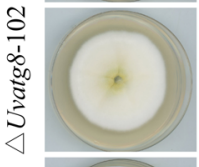

ب

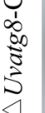
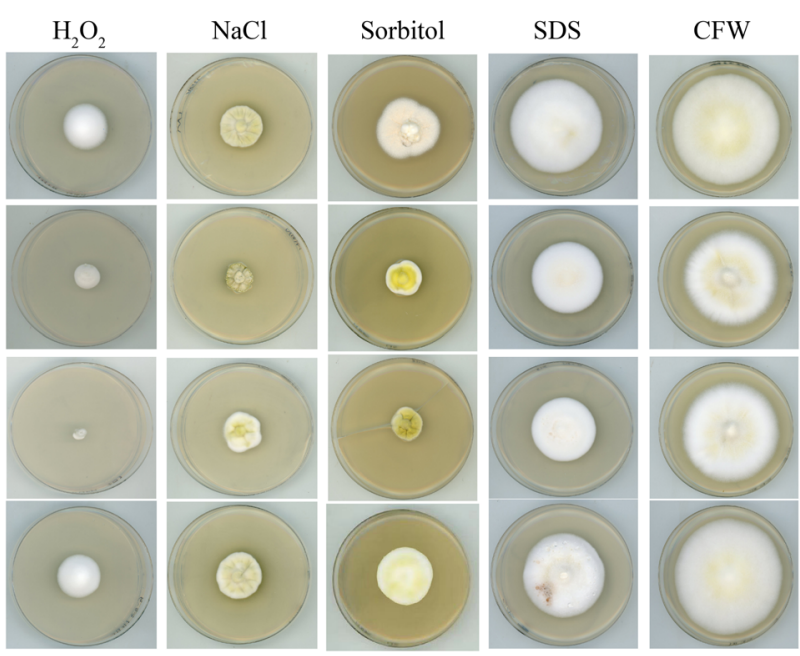

CR

b

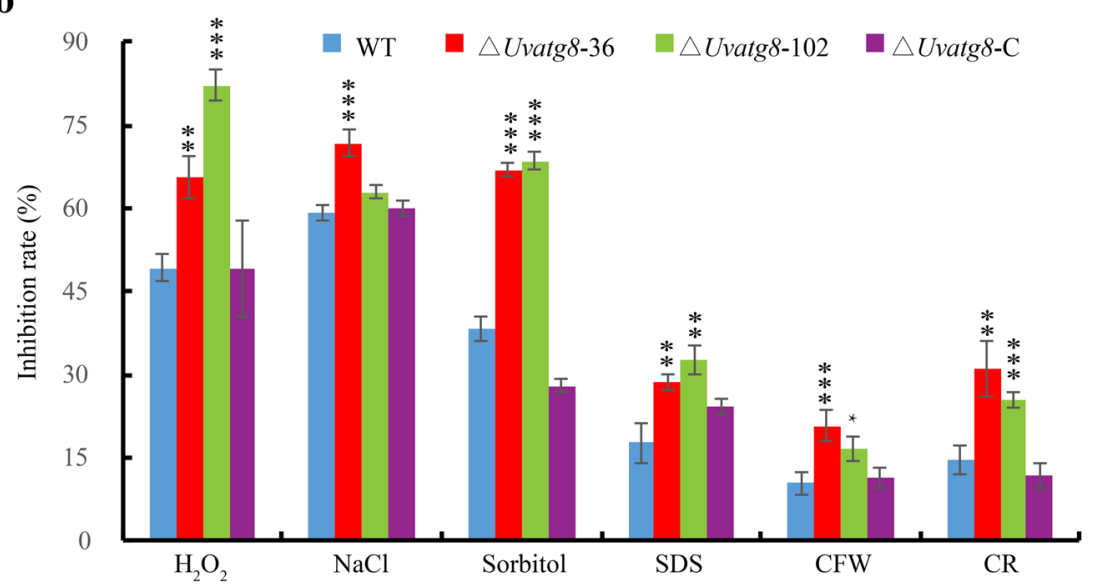

Fig. 5 Defects of the $\triangle$ Uvatg 8 mutants in response to different stresses. a, The represent strains were cultured on regular PSA plates or PSA plates with $0.03 \% \mathrm{H}_{2} \mathrm{O}_{2}, 0.4 \mathrm{M} \mathrm{NaCl}, 0.7 \mathrm{M}$ sorbitol, $0.03 \%$ Sodium dodecyl sulfate (SDS), $200 \mu \mathrm{g} / \mathrm{mL}$ Calcofluor white (CFW), $240 \mu \mathrm{g} / \mathrm{mL} \mathrm{Congo}$ red (CR) plates. Typical cultures were photographed after incubation for $15 \mathrm{~d}$ at $28^{\circ} \mathrm{C}$. b. Statistical analysis of inhibition rate of test strains under different stress conditions. The diameters of colonies were detected and analyzed. Similar results were obtained by three repeated experiments. The error bars represent the standard deviation and the asterisk represents the significant difference compared to the WT strain under the same conditions $\left({ }^{*}, p<0.01{ }^{* *}, p<0.005 ;{ }^{* * *}, p<0.001\right)$

deletion of $U v A T G 8$ significantly attenuated $U$. virens virulence, suggesting that $U v A T G 8$ is a key regulator of the pathogenicity of $U$. virens.

$U$. virens not only occupies rice grains, but also produces compounds, eg. Ustilaginoidins $\mathrm{O}, \mathrm{E}, \mathrm{F}$ and isochaetochromin B2, which are toxic to rice seeds ( $\mathrm{Lu}$ et al. 2015). In order to determine the inhibitory effect of toxic compounds on the germination of rice seeds, the filtrates were isolated from the PS cultures of $7 \mathrm{~d}$ old WT, $\Delta$ Uvatg8-36 and 102 , and $\Delta U v$ vatg8-C strains to treat rice seeds. As shown in Fig. $6 \mathrm{~d}$, the shoots of the rice treated by the filtrate of the $\Delta U v a t g 8$ strain culture was significantly longer than those of the WT and $\Delta U$ vatg8-C strains. Furthermore, the expression level of UvUSTA, which is a member of the gene cluster responsible for ustiloxin synthesis, in the deletion mutant of
UvATG8 was lower than that of the WT strain (Fig. 6e) (Tsukui et al. 2015; Zheng et al. 2016). These findings suggested that UvATG8 may have produced fewer toxic compounds which inhibit the shoot growth of rice shoots during rice seed germination.

\section{Serious Virulence Defects in $\Delta U v A t g 8$ Were Mainly Caused} by the Highly Decreased Formation of Secondary Spores

To further investigate the serious virulence defects caused by deletion of UvATG8, the infection processes of the WT, $\Delta U$ vatg8, and $\Delta U$ vatg8-C strains were determined. Although the structures of the conidia appeared to be normal, the conidial production of $\Delta U v a t g 8 \mathrm{mu}$ tant was highly reduced in comparison with that of the WT and $\Delta$ Uvatg8-C strains (Fig. 7a,b). Whereas the WT strain had formed $4.8 \times 10^{6}$ conidia/mL in $7 \mathrm{~d}$ old 
a
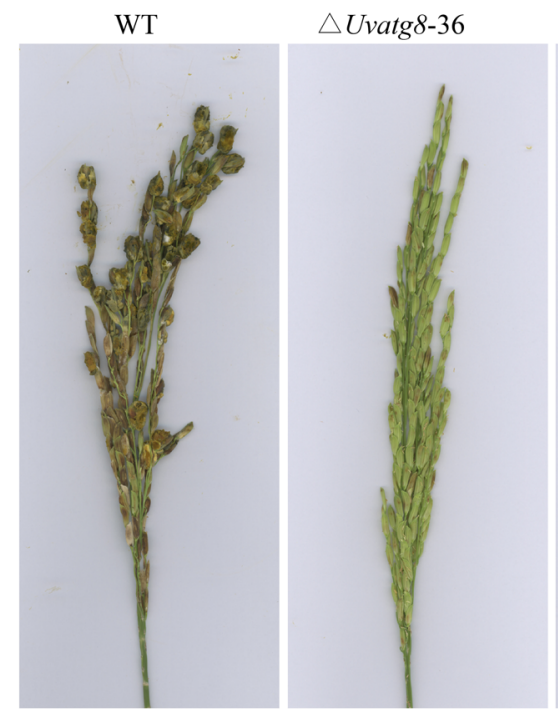

b

d

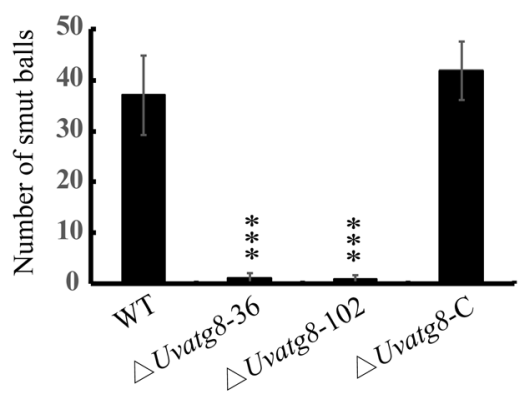

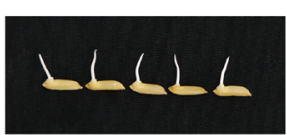

WT

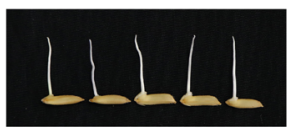

$\triangle$ Uvatg8-102

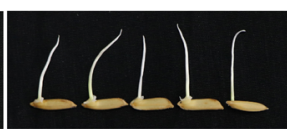

$\triangle$ Uvatg8-36

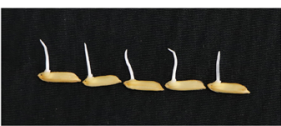

$\triangle$ Uvatg8-C $\triangle$ Uvatg8-102
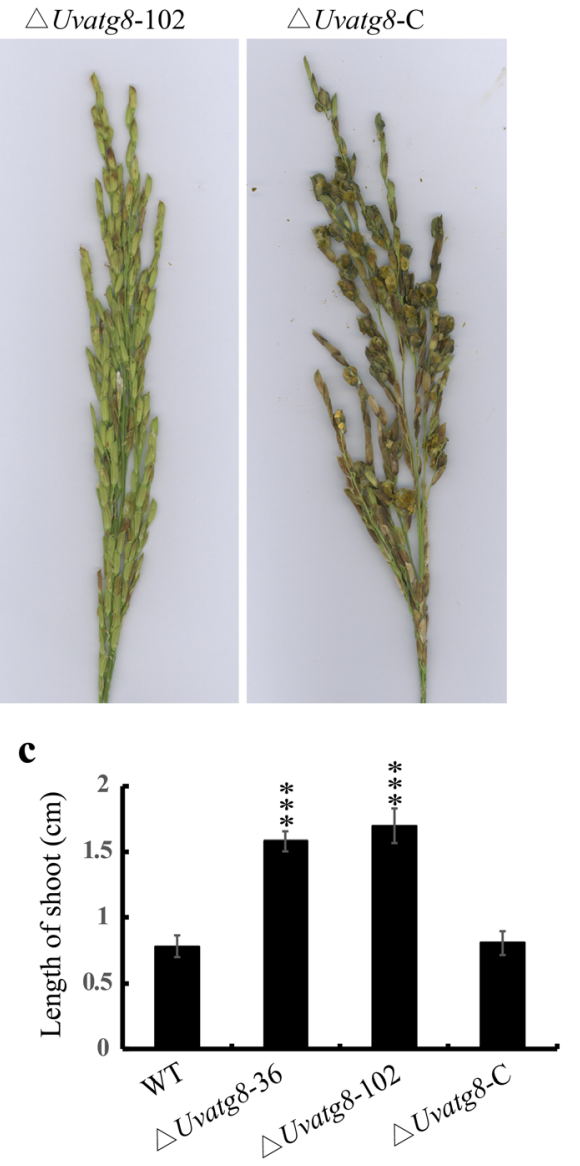

e

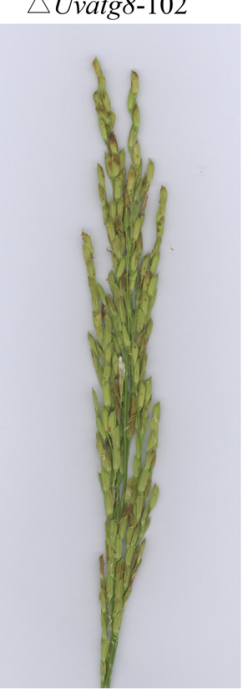

$\triangle$ Uvatg8-C

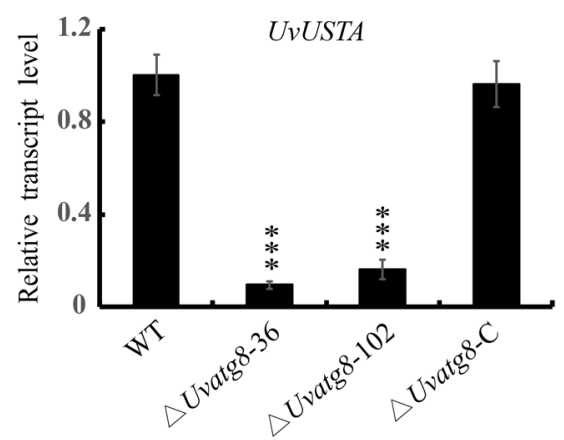

Fig. 6 Virulence assays of the $\Delta U$ Uvatg 8 mutants. a, Disease symptoms caused by the WT, $\triangle U$ vatg8, and $\Delta U$ vatg8-C strains on $21 \mathrm{~d}$ after inoculation. $b$, Statistical analysis results of the average number of false smut balls per spikelet. At least three independent biological experiments were performed with 30 inoculated panicles each time. c, Culture filtrates of the $\Delta U$ vatg 8 mutants displayed less inhibitory of rice seedling germination. The shoot lengths were measured and statistically analyzed after $7 \mathrm{~d}$ in $28^{\circ} \mathrm{C}$ illumination incubators. $d$, The growths of the rice shoots of the indicated strains were treated with testing culture filtrates. More than 100 rice seeds were sterilized with $0.1 \%$ potassium permanganate, then shifted to $35 \mathrm{~mL}$ culture filtrates at $28^{\circ} \mathrm{C}$ for $7 \mathrm{~d}$. e, qRT-PCR analysis of the expression of UVUSTA in the WT, $\triangle$ Uvatg8, and $\triangle$ Uvatg 8 -C strains. $\beta$-tubulin gene was used as the endogenous reference gene. Three independent experiments $(n=100)$ were carried out (mean \pm SD). ${ }^{* * *}$ indicates $p<0.001$

cultures, the $\Delta U v$ vatg8 mutants had produced less than $0.1 \times 10^{6}$ conidia/mL under the same conditions. This may have been the reason for the virulence deficiency of the $\Delta$ Uvatg8 strain. Furthermore, the GFP-UvAtg8 was likely presented in the vacuoles during conidiation (Fig. 7c), indicating that autophagy had occurred at that stage. However, when the same concentrations of conidia were inoculated, the infection efficiency of the 
$\mathbf{a}$

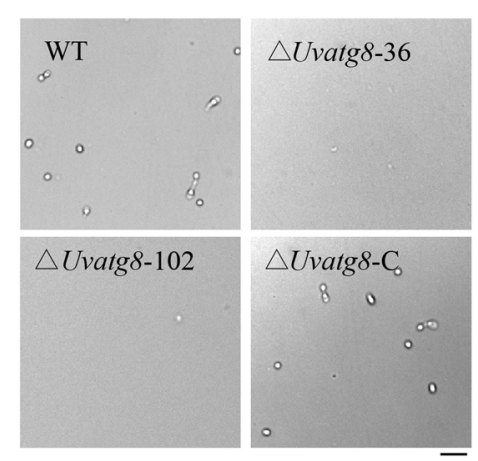

c

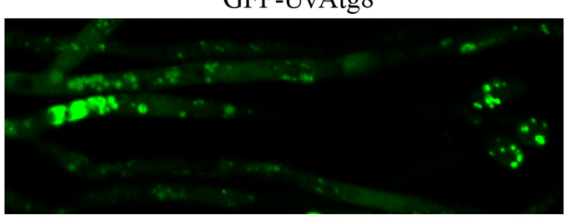

d

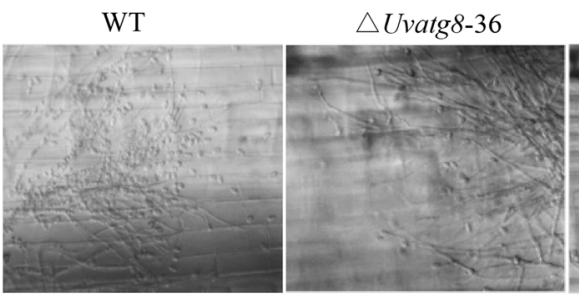

e
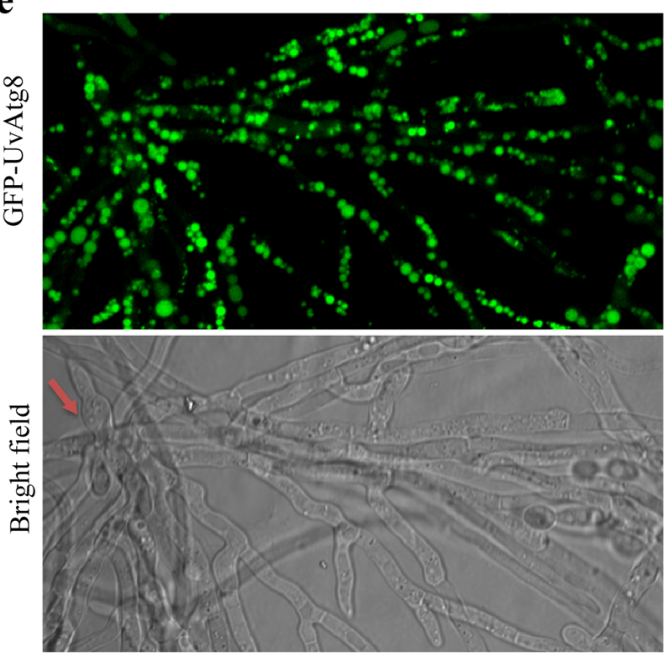

b

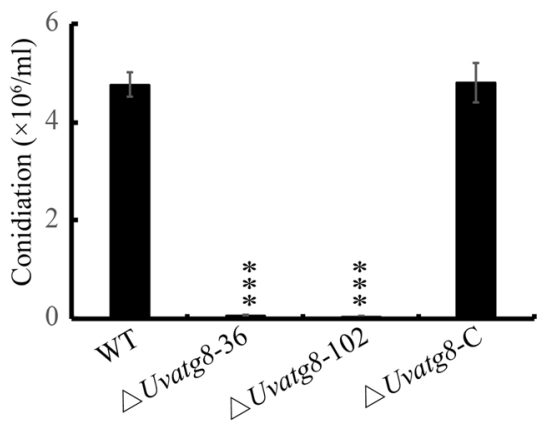

Bright field

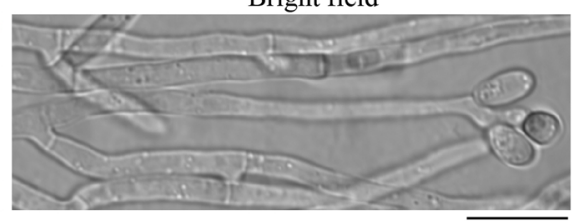

$\triangle$ Uvatg8-102
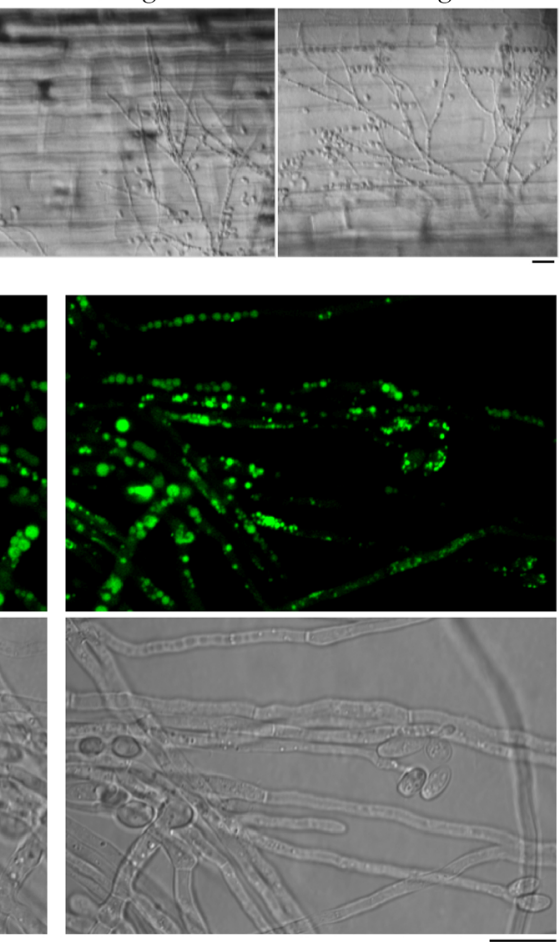

Fig. 7 Deletion of UVATG8 resulted in decreased conidiation. a and b, Conidiation of the tested strains. The strains were cultured in $50 \mathrm{~mL}$ of PS medium with $170 \mathrm{rpm}$ at $28^{\circ} \mathrm{C}$ for $7 \mathrm{~d}$ prior to the observation. Three repetitions were performed, with similar results obtained. c, The expression of GFP-UvAtg8 during conidiation. d, Conidial germination of U. virens on rice sheath. $5 \mu \mathrm{L}$ conidial droplets $\left(1 \times 10^{6} \mathrm{conidia} / \mathrm{mL}\right)$ were inoculated and incubated at $28^{\circ} \mathrm{C}$ for $3 \mathrm{~d}$. Photographs were taken under an Olympus BX53 microscope equipped with bright field optics. e, The GFPUvAtg8 was highly expressed, and autophagy had occurred during the secondary spore formation stage. The images were obtained using a confocal laser scanning microscope. Red arrow showed the conidial germination. Scale bar $=2.5 \mu \mathrm{m}$

$\Delta$ Uvatg8 strain was still observed to be highly decreased (Fig. 6a,b). Therefore, the results showed that, with the exception of the slightly slower growth and lower conidiation in the $\Delta U v a t g 8$ strain, there were definitely other reasons for the virulence deficiency of the $\Delta U v \operatorname{vatg} 8$ strain.

Next, the germination of the conidia from $\Delta U v \operatorname{vatg} 8$ mutant was detected. There were no significant 
differences observed in the germination of conidia between the WT strain and $\Delta U v a t g 8$ mutant. However, it should be noted that the formation of secondary spores was highly reduced in the $\Delta U$ vatg 8 mutant on the rice surface (Fig. 7d). During pathogenic processes of $U$. virens, the formation of secondary spores tends to greatly increase the amount of inoculation available to infect rice plants (Fan et al., 2013). Therefore, the highly reduced formation of secondary spores may have been the main reasons for the pathogenicity defects in the $\Delta$ Uvatg8 mutant. Meanwhile, the expression of GFPUvAtg8 was highly induced and targeted to the vacuoles (Fig. 7e, S1), suggesting that the UvAtg8 mediated autophagy occurrences and played an important role in formation of secondary spores during the infection of rice.

\section{Discussion}

$U$. virens has become one of the most devastating rice pathogens worldwide. Autophagy plays an important role in the maintenance of normal cell differentiation and development. However, at present there is no information available regarding the function of autophagy in $U$. virens virulence. In this study, through gene deletion, complementation, and localization analyses, it was successfully confirmed that UvAtg8 is required for autophagy, and it was indicated that GFP-UvAtg8 could be a useful marker for the study of autophagy in $U$. virens. Moreover, UvATG8 was also identified as key regulator of the pathogenicity of $U$. virens via its function in growth, various stresses responses, conidiation, and the formation of secondary spores during pathogenesis.

Atg8 is a key component of the autophagy pathway. During autophagy, Atg8 is localized to the autophagosomes, and then internalized in the vacuoles or lysosomes after fusion between the autophagosomes and vacuoles/lysosomes (Liu et al. 2016; Zong et al. 2016; Hofius et al. 2017). In this study, we found that GFPUvAtg8 could be a marker for autophagy in $U$. virens. First, UvATG8 is essential for autophagy, and the deletion of UvATG8 resulted in blocked autophagic pathway in $U$. virens. These results suggested that the functions of UvAtg8 are conserved among various species. Therefore, fluorescent-marker-tagged UvAtg8 may be used to visualize the occurrences of autophagy similar to Atg8 in other organisms (Zong et al. 2016; Deng et al. 2009). Second, the GFP-UvATG8 (with only one copy of UvATG8) functions properly in $U$. virens, and the fluorescence intensities and localization of GFP-UvAtg8 were changed by the autophagy-induced conditions. The vegetative growths of the GFP-UvATG8 strain are comparable to the WT strain under both normal and nutrient starvation conditions. Moreover, the expression of GFP-UvAtg8 was highly induced in the SD-N medium (nitrogen starvation medium), and was considered to have induced autophagy. Furthermore, Western blot assay could be performed to show the level of GFPUvAtg8 to monitor the quantity of the autophagy in $U$. virens. In conclusion, GFP-UvAtg8 could serve as a good marker for monitoring the autophagy in $U$. virens.

Although the genomic sequences of $U$. virens have been released, there are only a small number of pathogenicity-related genes which have been functionally characterized and experimentally verified as pathogenic factors (Qiu et al. 2019). These pathogenic factors include low-affinity iron transporter Uvt3277, hypothetical protein UvPro1, adenylate cyclase UvAc1, phosphodiesterase UvPdeH, effector Scre2 (Uv-1261), Bax inhibitor UvBI-1, two protein kinases UvPmk1 and UvCDC2, and transcription factor UvCom1 (Zheng et al. 2017; Xie et al. 2019; Tang et al. 2019; Lv et al. 2016; Guo et al. 2019; Fang et al. 2019; Fan et al. 2019; Chen et al. 2019). In this study, UvATG8 was characterized as a pathogenic factor. Loss of UvATG8 resulted in impaired pathogenesis. The slightly hypha growth defects and lower conidiation may contribute to the pathogenicity defects in $U$. virens. However, these may not be the major causes of the serious defects in virulence in the $\Delta U v A \operatorname{tg} 8$ mutant, since the infection efficiency of the $\Delta U v a \operatorname{tg} 8$ strain was still highly decreased in the inoculation assays with the same concentrations of conidia. $U$. virens has been reported to have epiphytic characteristics (Fan et al., 2013). In the epiphytic colonization of $U$. virens, the rapid production of large numbers of secondary spores greatly increases the amount of inoculation potential of $U$. virens on rice spikelets, which will subsequently lead to the increased occurrences of rice smut disease (Fan et al., 2013). In the $\Delta U v A \operatorname{tg} 8$ mutant, the generation of secondary spores was highly reduced. Moreover, the expression of the GFP-UvAtg8 was highly induced during secondary spore formation, indicating that the UvAtg8mediated autophagy regulates secondary spore formation to promote the infection of $U$. virens. In addition to the spore formation, UvAtg8 can be also important for the infection processes, because $U$. virens may depend on autophagic utilization of its own nutritional storage to initiate infection before getting access to host nutrients. Taken together, UvAtg8 affects the pathogenicity by regulating the hypha growth, conidiation, and, most importantly, the formation of secondary spores in $U$. virens.

In conclusion, our study indicated that UvAtg8 is necessary for the fungal growth, stress responses, conidiation, secondary spore formation, and pathogenicity in $U$. virens. In addition, GFP-UvAtg8 provided a good marker for monitoring of the autophagy in $U$. virens. Furthermore, the results of this study facilitated a deeper understanding of the pathogenic molecular mechanism of $U$. 
virens, that autophagy plays an important role in the pathogenicity of $U$. virens.

\section{Materials and Methods Sequence Analysis}

The sequences of the genes and proteins used in this study were downloaded from the National Center for Biotechnology Information (NCBI, https://www.ncbi. nlm.nih.gov/). The protein sequence alignments were processed using EPSript 3.0, and the phylogenetic analyses were performed using MEGA 5.0 with a neighborjoining algorithm (Robert and Gouet 2014).

\section{Fungal Strains and Culture Media}

The $U$. virens WT strain HWD-2 was kindly provided by Professor Junbin Huang from Huazhong Agriculture University (Hubei, People's Republic of China). The routine culturing of the $U$. virens strain was carried out on potato sucrose agar (PSA, potato $200 \mathrm{~g} / \mathrm{L}$, sucrose $20 \mathrm{~g} /$ $\mathrm{L}$, and agar $20 \mathrm{~g} / \mathrm{L}$ ) medium at $28^{\circ} \mathrm{C}$. The DNA and RNA samples were collected from mycelia which had been cultured in the PS (potato $200 \mathrm{~g} / \mathrm{L}$, sucrose $20 \mathrm{~g} / \mathrm{L}$ ) medium for $7 \mathrm{~d}$.

For the conidia concentrations, six agar plugs with mycelium were inoculated into a $100 \mathrm{~mL}$ flask, then $50 \mathrm{~mL}$ of liquid PS medium was added. The agar plugs were vibrated at $170 \mathrm{rpm}$ for $7 \mathrm{~d}$ at $28^{\circ} \mathrm{C}$. The filtration of the samples was used to measure the conidia concentration and conidia germination. The conidia were germinated on rice sheath.

To test the sensitivity to various abiotic stress conditions, the $U$. virens strains were measured after grown on the PSA medium and PSA medium with $0.03 \% \mathrm{H}_{2} \mathrm{O}_{2}$, $0.4 \mathrm{M} \mathrm{NaCl}, 0.7 \mathrm{M}$ Sorbitol, 0.03\% SDS, $200 \mu \mathrm{g} / \mathrm{mL}$ CFW or $240 \mu \mathrm{g} / \mathrm{mL} \mathrm{CR}$ at $28^{\circ} \mathrm{C}$ for $15 \mathrm{~d}$. For the nutrient starvation, the $\mathrm{SD}$ (Yeast nitrogen base without amino acids and $1.7 \mathrm{~g} / \mathrm{L}$, Ammonium sulfate, $5 \mathrm{~g} / \mathrm{L}$ glucose $20 \mathrm{~g} / \mathrm{L}$ ) medium and SD-N (Yeast nitrogen base without amino acids and $1.7 \mathrm{~g} / \mathrm{L}$, glucose $20 \mathrm{~g} / \mathrm{L}$ ) medium was used. The formula of the inhibition rate was as follows: Inhibition rate $=$ (average of strain colony diameters on the PSA the average of strain colony diameters on the PSA with different chemicals)/average of the strain colony diameters on the PSA $\times 100 \%$. All of the experiments were repeated three times with three replicates each time.

\section{Construction of the $\Delta U$ vatg 8 Strains and Complementation Analyses}

The UvATG8 gene (UV8b_6970) deletion mutant was generated using a one-step gene replacement strategy. Briefly, approximately $1 \mathrm{~Kb}$ upstream and downstream flanking sequences of $U v A T G 8$ were PCR amplified and ligated sequentially to flank of the hygromycin phosphotransferase gene cassette in pFGL821 (Addgene, 58,224).
Primers used to amplify the flanking sequences of the UvATG8 gene were shown in Table S1. The final plasmid construct was confirmed by sequencing, and subsequently introduced into the HWD-2 strain by Agrobacterium tumefaciens-mediated transformation (ATMT) to replace the UvATG8 gene (Tang et al. 2019). For complementation analysis, the full-length genomic copy with the promoter of UvATG8 was amplified with UvATG8-F and UvATG8-R (Table S1), and then inserted into pFGL822 (Addgene, 58,226). The resultant plasmid was transformed into the $\Delta U$ vatg8 strain.

The correct transformants of the $\Delta U v a t g 8$ and complementation assay in this study were ascertained using Southern blot and/or qRT-PCR analysis. For the Southern blot analysis, the genomic DNA samples from the WT and $\Delta U$ vatg8 strains were extracted and digested with $\mathrm{Xba}$ I. The digested products were then separated through $0.8 \%$ agarose gel and mounted onto positively charged nylon membrane (GE Healthcare, Buckinghamshire, UK). Then, the DIG-labeled UvATG8 probe, which was amplified from the genomic DNA of the WT strain using the primers UvATG8-probeF/R (Table S1), was used to hybridize with the $X b a$ I digested genomic DNA of the WT and $\Delta U$ vatg8 mutants. The hybridization process was performed following manufacturing instructions provided by Amersham ${ }^{\text {Tn }}$ AlkPhos Direct Labeling Reagents (GE Healthcare, Buckinghamshire, UK).

\section{qRT-PCR Analysis}

In regard to the qRT-PCR, the total RNA from the mycelium cultured in PS medium was extracted using the Fungal RNA Kit 200 (OMEGA). The reserve transcriptional analysis was performed using Primescript ${ }^{\mathrm{m}}$ RT reagent kit with gDNA Eraser and TB Green ${ }^{\text {Tm }}$ Premix Ex Taq ${ }^{\text {mi }}$ (Tli RnaseH Plus) (Takara) as the instrument. The $\beta$-tubulin gene was used as the endogenous reference gene (Table S1), and the relative expression level of the gene was calculated using the $2-{ }^{\Delta \Delta} \mathrm{Ct}$ method. Three biological replicates were performed to calculate the mean and standard deviation.

\section{Generation of the GFP-UvATG8 Strain and Western Blot Analysis}

For generating the plasmid vector to express the GFPUvATG8, approximately $1 \mathrm{~Kb}$ of downstream flanking sequences of UvATG8 were PCR amplified and ligated to $p F G L 821$. Then, $1 \mathrm{~Kb}$ of promoter region of UvATG8, $e G F P$, and the CDS of UvATG8 were inserted into resulted construct to obtain the GFP-UvATG8 (Table S1). The sequences of the plasmid were confirmed by sequencing and were subsequently introduced into the WT strain by ATMT to replace UvATG8. The transformants were confirmed by PCR and epifluorescence microscopic observation. 
For the induction of autophagy, the GFP-UvATG8 strain was grown in the PS (PS, potato $200 \mathrm{~g} / \mathrm{L}$, sucrose $20 \mathrm{~g} / \mathrm{L}$ ) medium for $3 \mathrm{~d}$, followed by starvation in SD-N (Yeast nitrogen base without amino acids and $1.7 \mathrm{~g} / \mathrm{L}$, glucose $20 \mathrm{~g} /$ L) medium for 0,6 , and $12 \mathrm{~h}$, respectively. The mycelia grown in the PS medium were used as control. Total proteins were extracted from the mycelia grown under the requisite conditions as described (Liang et al. 2018). The protein samples were quantified using a BCA protein content assay kit (Cat. No. C503021, Beyotime, China). Equal total proteins were loaded and separated on a $12 \%$ SDSPAGE (Sodium dodecylsulphate polyacrylamide gel electrophoresis) (Bio-Rad, Hercules, USA), which were then transferred to a PVDF (Polyvinylidene fluoride) membrane. The anti-GFP antibody (Cat. ab32146, Abcam, UK) and an anti-rabbit IgG (Cat. ab205718, abcam, UK) were used for the blotting processes. The samples were also hybridized with the monoclonal anti-GAPDH antibody (Cat. No. R1208-3, HuaBio, China) to be an internal reference. All of the experiments were repeated three times.

\section{Live Cell Imaging and Image Processing}

To visualize the vacuole, the mycelia were incubated with $10 \mu \mathrm{M}$ CellTracker ${ }^{\text {tm }}$ Blue CMAC Dye (Molecular Probes C2110) for 20 mins at $28^{\circ} \mathrm{C}$. The samples were washed with water prior to the microscopic observation.

The live cell imaging of this study was performed using a Zeiss LSM 700 inverted confocal microscope (Carl Zeiss, Inc) equipped with a Plan-Apochromat 63 (NA 1.40) oil immersion lens. EGFP and CMAC excitations were performed at $488 \mathrm{~nm}(\mathrm{Em} .505-530 \mathrm{~nm})$ and $405 \mathrm{~nm}$ (Em. 430-470 nm), respectively. The images were processed in the Image J program from National Institutes of Health (http://rsb.info.nih.gov/) and arranged in Adobe Illustrator CS6.

\section{Plant Infection and Toxicity Assays}

For the infection assay, a mixture of mycelia and conidia $\left(10^{6}\right.$ conidia $\left./ \mathrm{mL}\right)$ was broken down for $3 \mathrm{~min}$ in a juice blender. Then, the conidia suspension was adjusted to $1 \times 10^{6}$ conidia/mL to inject the panicles of selected rice plants (Oryza sativa L., cultivar Wanxian98) at the booting stage (6-7 d before heading). The inoculated plants were grown in a growth chamber under $12 \mathrm{~h}$ light/dark conditions, at a temperature of $25^{\circ} \mathrm{C}$ and with $90 \%$ humidity. Smut balls were assessed and recorded by scanning the leaves at $21 \mathrm{~d}$ post inoculation. The values were represented as the mean $\pm \mathrm{SD}$ from three independent experiments, with more than 30 inoculated panicles each time. Toxicity assays with culture filtrates were performed as described using Wanxian98 seeds (Zheng et al. 2016). All of the experiments in this section were performed in three independent biological experiments with three replicates in each test.

\section{Supplementary information}

Supplementary information accompanies this paper at https://doi.org/10. 1186/s12284-020-00418-z.

Additional file 1: Table S1. Primers used in this study.

Additional file 2: Fig. S1. The GFP-UvAtg8 was highly expressed during the secondary spore formation stage on rice.

\begin{abstract}
Abbreviations
ATG: autophagy-related; CMAC: 7-amino-4-chloromethylcoumarin; CFW: Calcofluor white; CR: Congo red; d: days; Kb: kilobases; F. graminearum: Fusarium graminearum; GFP: green fluorescent protein; h: hours; M. oryzae: Magnaporthe oryzae; mins: minutes; PMSF: Phenylmethanesulfonyl fluoride; PVDF: Polyvinylidene fluoride; PS: potato sucrose medium; PSA: potato sucrose agar medium; $S$. cerevisiae: Saccharomyces cerevisiae; SD-N: synthetic dropout medium with nitrogen; SDS: Sodium dodecyl sulfate; SDS-PAGE: sodium dodecylsulphate polyacrylamide gel electrophoresis; Ustilaginoidea virens: U. virens; WT: wild type.
\end{abstract}

\section{Acknowledgements}

This project was supported by the Chinese Academy of Agricultural Sciences under the "Elite Youth" program, the Agricultural Sciences and Technologies Innovation Program. We thank Prof. Junbin Huang for providing the HWD-2 strain.

\section{Authors' Contributions}

YJK planned and designed the research. SM, MX, JSJ, CCW, JHQ, and HBS performed experiments, conducted field work, and analyzed data etc. SM and YJK wrote the manuscript. The author(s) read and approved the final manuscript.

\section{Funding}

This research was funded by Zhejiang Provincial Natural Science Foundation of China, grant number "LQ19C140004" and key R\&D project of Zhejiang Province, grant number "2019C02018".

\section{Availability of Data and Materials}

The datasets supporting the conclusions of this article are included within the article and its additional files.

Ethics Approval and Consent to Participate

Not applicable.

Consent for Publication

Not applicable.

Competing Interests

There is no conflict of interest.

\section{Author details}

${ }^{1}$ State Key Laboratory of Rice Biology, China National Rice Research Institute, Hangzhou 311400, China. ${ }^{2}$ Key Laboratory of Three Gorges Regional Plant Genetics \& Germplasm Enhancement (CTGU)/Biotechnology Research Center, China Three Gorges University, Yichang 443000, China.

Received: 17 November 2019 Accepted: 6 August 2020

Published online: 12 August 2020

\section{References}

Chen X, Hai D, Tang JT, Liu H, Huang JB, Luo CX et al (2019) UvCom1 is an important regulator required for development and infection in the rice false smut fungus Ustilaginoidea virens. Phytopathology. https://doi.org/10.1094/ PHYTO-05-19-0179-R

Deng YZ, Ramos-Pamplona M, Naqvi NI (2009) Autophagy-assisted glycogen catabolism regulates asexual differentiation in Magnaporthe oryzae. Autophagy 5(1):33-43. https://doi.org/10.4161/auto.5.1.7175

Fan J, Du N, Li L, Li GB, Wang YQ, Zhou YF et al (2019) A core effector UV_126 promotes Ustilaginoidea virens infection via spatiotemporally suppressing 
plant defense. Phytopathol Res 1(1):11. https://doi.org/10.1186/s42483-0190019-5

Fan J, Guo XY, Huang F, Li Y, Liu YF, Wang WM (2013) Epiphytic colonization of ustilaginoidea virens on biotic and abiotic surfaces implies the widespread presence of primary inoculum for rice false smut disease. Plant Pathol 63: 937-945. https://doi.org/10.1111/ppa.12167

Fan J, Yang J, Wang YQ, Li GB, Li Y, Huang F et al (2016) Current understanding on Villosiclava virens, a unique flower-infecting fungus causing rice false smut disease. Mol Plant Pathol 17(9):1321-1330. https://doi.org/10.1111/mpp. 12362

Fang A, Gao H, Zhang N, Zheng X, Qiu S, Li Y et al (2019) A novel effector gene SCRE2 contributes to full virulence of Ustilaginoidea virens to rice. Front Microbiol 10:845. https://doi.org/10.3389/fmicb.2019.00845

Guo W, Gao Y, Yu Z, Xiao Y, Zhang Z, Zhang H (2019) The adenylate cyclase UvAc1 and phosphodiesterase UvPdeH control the intracellular cAMP level, development, and pathogenicity of the rice false smut fungus Ustilaginoidea virens. Fungal Genet Biol 129:65-73. https://doi.org/10.1016/j.fgb.2019.04.017

Hanada T, Noda NN, Satomi Y, Ichimura Y, Fujioka Y, Takao T et al (2007) The Atg12-Atg5 conjugate has a novel E3-like activity for protein lipidation in autophagy. J Biol Chem 282(52):37298-37302. https://doi.org/10.1074/jbc C700195200

Hofius D, Li L, Hafren A, Coll NS (2017) Autophagy as an emerging arena for plant-pathogen interactions. Curr Opin Plant Biol 38:117-123. https://doi.org/ 10.1016/j.pbi.2017.04.017

Ichimura Y, Kirisako T, Takao T, Satomi Y, Shimonishi Y, Ishihara N et al (2000) A ubiquitin-like system mediates protein lipidation. Nature 408(6811):488-492. https://doi.org/10.1038/35044114

Jia Q, Lv B, Guo M, Luo C, Zheng L, Hsiang T et al (2014) Effect of rice growth stage, temperature, relative humidity and wetness duration on infection of rice panicles by Villosiclava virens. Eur J Plant Pathol 141(1):15-25. https://doi. org/10.1007/s10658-014-0516-4

Josefsen L, Droce A, Sondergaard TE, Sorensen JL, Bormann J, Schafer W et al (2012) Autophagy provides nutrients for nonassimilating fungal structures and is necessary for plant colonization but not for infection in the necrotrophic plant pathogen Fusarium graminearum. Autophagy 8(3):326337. https://doi.org/10.4161/auto.18705

Ladhalakshmi D, Laha GS, Singh R, Karthikeyan A, Mangrauthia SK, Sundaram RM et al (2012) Isolation and characterization of Ustilaginoidea virens and survey of false smut disease of rice in India. Phytoparasitica 40(2):171-176. https://doi.org/10.1007/s12600-011-0214-0

Liang Y, Han Y, Wang C, Jiang C, Xu JR (2018) Targeted deletion of the USTA and UvSLT2 genes efficiently in Ustilaginoidea virens with the CRISPR-Cas9 system. Front Plant Sci 9:699. https://doi.org/10.3389/fpls.2018.00699

Lin X, Bian Y, Mou R, Cao Z, Cao Z, Zhu Z et al (2018) Isolation, identification, and characterization of Ustilaginoidea virens from rice false smut balls with high ustilotoxin production potential. J Basic Microbiol 58(8):670-678. https://doi. org/10.1002/jobm.201800167

Liu XH, Xu F, Snyder JH, Shi HB, Lu JP, Lin FC (2016) Autophagy in plant pathogenic fungi. Semin Cell Dev Biol 57:128-137. https://doi.org/10.1016/j. semcdb.2016.03.022

Lu S, Sun W, Meng J, Wang A, Wang X, Tian J et al (2015) Bioactive bis-naphthogamma-pyrones from rice false smut pathogen Ustilaginoidea virens. J Agric Food Chem 63(13):3501-3508. https://doi.org/10.1021/acs.jafc.5b00694

Lv B, Zheng L, Liu H, Tang J, Hsiang T, Huang J (2016) Use of random T-DNA mutagenesis in identification of gene UVPRO1, a regulator of conidiation, stress response, and virulence in Ustilaginoidea virens. Front Microbiol 7:2086. https://doi.org/10.3389/fmicb.2016.02086

Meng J, Sun W, Mao Z, Xu D, Wang X, Lu S et al (2015) Main Ustilaginoidins and their distribution in rice false dmut balls. Toxins (Basel) 7(10):4023-4034. https://doi.org/10.3390/toxins 7104023

Nadal M, Gold SE (2010) The autophagy genes ATG8 and ATG1 affect morphogenesis and pathogenicity in Ustilago maydis. Mol Plant Pathol 11(4): 463-478. https://doi.org/10.1111/j.1364-3703.2010.00620.x

Nakatogawa H, Ichimura Y, Ohsumi Y (2007) Atg8, a ubiquitin-like protein required for autophagosome formation, mediates membrane tethering and hemifusion. Cell 130(1):165-178. https://doi.org/10.1016/j.cell.2007.05.021

Nessa B, Salam MU, Haque AHMM, Biswas JK, Kabir MS, Macleod WJ et al (2015) Spatial pattern of natural spread of rice false smut (Ustilaginoidea virens) disease in fields. Am J Agric Biol Sci 10(2):63-73. https://doi.org/10.3844/ ajabssp.2015.63.73
Qiu J, Meng S, Deng Y, Huang S, Kou Y (2019) Ustilaginoidea virens: a fungus infects rice flower and threats world rice production. Rice Sci 26(4):199-206. https://doi.org/10.1016/.j.rsci.2018.10.007

Ren W, Liu N, Sang C, Shi D, Zhou M, Chen C et al (2018) The autophagy gene BCATG8 regulates the vegetative differentiation and pathogenicity of Botrytis cinerea. Appl Environ Microbiol 84(11). https://doi.org/10.1128/aem.02455-17

Robert X, Gouet P (2014) Deciphering key features in protein structures with the new ENDscript server. Nucleic Acids Res 42:W320-W324. https://doi.org/10. 1093/nar/gku316

Shi L, Wang J, Quan R, Yang F, Shang J, Chen B (2019) CpATG8, a homolog of yeast autophagy protein ATG8, is required for pathogenesis and hypovirus accumulation in the Chest Blight fungus. Front Cell Infect Microbiol 9:222. https://doi.org/10.3389/fcimb.2019.00222

Sumita T, Izumitsu K, Tanaka C (2017) Characterization of the autophagy-related gene BmATG8 in Bipolaris maydis. Fungal Biol 121(9):785-797. https://doi.org/ 10.1016/j.funbio.2017.05.008

Sun W, Wang A, Xu D, Wang W, Meng J, Dai J et al (2017) New ustilaginoidins from rice false smut balls caused by villosiclava virens and their phytotoxic and cytotoxic activities. 65(25): 5151-60. doi: https://doi.org/10.1021/acs.jafc. $7 \mathrm{~b} 01791$

Tang J, Bai J, Chen X, Zheng L, Liu H, Huang J (2019) Two protein kinases UvPmk1 and UVCDC2 with significant functions in conidiation, stress response and pathogenicity of rice false smut fungus Ustilaginoidea virens. Curr Genet. https://doi.org/10.1007/s00294-019-01029-y

Tsukui T, Nagano N, Umemura M, Kumagai T, Terai G, Machida M et al (2015) Ustiloxins, fungal cyclic peptides, are ribosomally synthesized in Ustilaginoidea virens. Bioinformatics 31(7):981-985. https://doi.org/10.1093/ bioinformatics/btu753

Veneault-Fourrey C, Barooah M, Egan M, Wakley G, Talbot NJ (2006) Autophagic fungal cell death is necessary for infection by the rice blast fungus. Science 312(5773):580-583. https://doi.org/10.1126/science.1124550

Wang X, Wang J, Lai D, Wang W, Dai J, Zhou L et al (2017) Ustiloxin G, a new cyclopeptide mycotoxin from rice false smut balls. Toxins (Basel) 9(2). https://doi.org/10.3390/toxins9020054

Xie S, Wang Y, Wei W, Li C, Liu Y, Qu J et al (2019) The Bax inhibitor UvBl-1, a negative regulator of mycelial growth and conidiation, mediates stress response and is critical for pathogenicity of the rice false smut fungus Ustilaginoidea virens. Curr Genet 65(5):1185-1197. https://doi.org/10.1007/ s00294-019-00970-2

Yin Z, Feng W, Chen C, Xu J, Li Y, Yang L et al (2019) Shedding light on autophagy coordinating with cell wall integrity signaling to govern pathogenicity of Magnaporthe oryzae. Autophagy:1-17. https://doi.org/10 1080/15548627.2019.1644075

Yoshimura K, Shibata M, Koike M, Gotoh K, Fukaya M, Watanabe M et al (2006) Effects of RNA interference of Atg $4 B$ on the limited proteolysis of LC3 in PC12 cells and expression of Atg $4 B$ in various rat tissues. Autophagy 2(3): 200-208. https://doi.org/10.4161/auto.2744

Zheng D, Wang Y, Han Y, Xu JR, Wang C (2016) UvHOG1 is important for hyphal growth and stress responses in the rice false smut fungus Ustilaginoidea virens. Sci Rep 6:24824. https://doi.org/10.1038/srep24824

Zheng MT, Ding H, Huang L, Wang YH, Yu MN, Zheng R et al (2017) Low-affinity iron transport protein Uvt3277 is important for pathogenesis in the rice false smut fungus Ustilaginoidea virens. Curr Genet 63(1):131-144. https://doi.org/ 10.1007/s00294-016-0620-4

Zhu XM, Li L, Wu M, Liang S, Shi HB, Liu XH et al (2019) Current opinions on autophagy in pathogenicity of fungi. Virulence 10(1):481-489. https://doi.org/ 10.1080/21505594.2018.1551011

Zong WX, Zorzano A, Zughaier SM (2016) Guidelines for the use and interpretation of assays for monitoring autophagy (3rd edition). Autophagy 12(1):1-222. https://doi.org/10.1080/15548627.2015.1100356

\section{Publisher's Note}

Springer Nature remains neutral with regard to jurisdictional claims in published maps and institutional affiliations. 